FUNKHOUSER, J. B., and DAVIS, H. W. (1952), f. Nerv. Ment. Dis., 116, 131 .

GUiRaud, P., and Mallet, J. (1948), Ann. Méd. Psychol., I, 202.

GULPERIN, E. A, (1949), Neuropathol. \& Psychiat., 18, 52.

HILL, D. (1949), Brit. Med. Bull., 6, 36.

HUSTON, P. E., and LOCHER, L. M. (1948), Arch. N. \& P., 59, 385 .

JENTOFT, B. (1949), Ұ. Ment. Sci., 95, 651 .

JETTER, W. W. (1944), Arch. Neurol. Psychiat., 51, 557.

KALDECK, R. (1948), Arch. Neurol. \&5 Psychiat., 59, 229.

KALINOWSKY, L., and KENNEDY, F. (1943), f. Nerv. Ment. Dis., 98, 56 .

KAUNTZE, R., and PARSONS-SMITH, G. (1948), Brit. Heart f., I0, 57.

KINO, F. F., and THORPE, F. T. (1946), F. Ment. Sci., $92,138$. KLEINSCHMIDT, H. J., et al. (1949), Psychiat. Quart., 23, 145. KOLB, L., and VOGEL, V. H. (1942), Amer. F. Psychiat., 99, 90. LIBAN, E., et al. (1951), F. Neuropath. \& Exper. Neurol., 10, 309. LINGLEY, J. R., ROBBINS, L. L. (1947), Radiology, 48, 124.

MARCHAND, L., and MASSON, J. (1947), Ann. Med. Psychol., II, 556 .

MEYER, A., and TEARE, D. (1945), Brit. Med. F., ii, 42.

NAPIER, F. J. (1944), F. Ment. Sci., 90, 875.

NIELSEN, J. M. (1950), Bull. Los. Ang. Neurol. Soc., 15, 200. O'FLANAGAN, P. M., and TAYLOR, R. B. (1950), Brit. Med. F., ii, 444.

PELlETIER, A., and PARADIS, G. (1951), Laval. Méd., 16, 478. PENNACHI, F. (1949), Ann. Osp. Psichiat. Perugia, 43, 1.
PENTA, P. (1947), Il Progresso Medico, 3, 139.

PERRY, H. A., LEVY, S. (1949), F. Nerv. Ment. Dis., 110, 497.

PHILLIP, E. (1952), Z. Klin. Med., 149, 520.

POLONI, A. (1949), Il Cervello, 25, 201.

RASKIN, N., and JOHNSON, R. S. (1951), Dis. Nerv. Syst., ¿

12, 373 .

RIESE, W. (1948), f. Neuropathol. E' Exper. Neurol., 7, 98. RIESE, W., and FULTZ, G. S. (1949), Amer. $\mathcal{F}$. Psychiat., 106, 206. ROGG, G. S. (1953), Quoted : Amer. F. Psychiat., 110, 473.

ROTH, M. (1952), f. Ment. Sci., 98, 44.

ROTH, M., and ROSIE, J. M. (1953), F. Ment. Sci., 99, ro3.

RIVOLTA, G. (1949), Il Policlinico, 56, 748.

SALAN, I., and CARMICHAEL, D. M. (1948), F. Amer. Med. Ass., 138, 205.

SALM, H. (1949), Mediz. Klinik., 44, 178.

SCHEIDEGGER, S. (1950), Schweiz. Z. Allg. Path., 13, 795. C SCHULTE, W., and DREYER, R. (1950), Der Nervenarzt, 21, 175. SIMON, J. L. (1948), f. Nerv. Ment. Dis., 107, 579.

SISLER, G. C., WILT, J. C. (1953), Amer. F. Psychiat., Iro, 354. $\vec{\omega}$ SPIEGEL, E. A., and SPIEGEL-ADOLF, M. (1953), Confinia Neurol., 13, 38 .

SPRAGUE, D. W., and TAYLOR, R. C. (1948), Ohio State Med. $¥$. ., 44, $5 \mathrm{I}$.

VITELLO, A. (1949), Rassegna d. Stud. Psichiat., 38, 59.

WILL, O. A., et al. (1948), $\mathcal{F}$. Nerv. Ment. Dis., 107, 105.

WILL, A., Dis. 105, 637 .

WOODS, A. W. W. B. (1954), in press.

\title{
THE MANAGEMENT OF PORTAL HYPERTENSION
}

\author{
By A. I. S. MAcPherson, Ch.M., F.R.C.S.E. \\ From the Department of Surgery, University of Edinburgh
}

The normal portal venous blood pressure is higher than the pressure in a somatic vein of similar size because the portal blood has to traverse the sinusoids of the liver before it reaches the systemic circulation. The range of normal portal pressure is $6-12 \mathrm{~cm}$. of saline. If a further obstruction to portal flow is gradually interposed, there will ensue a rise in portal venous pressure, sometimes to $30-40 \mathrm{~cm}$. of saline and the development of collateral channels for the return of the portal blood to the general circulation. Such obstructions may occur inside or outside the liver. Extra-hepatic obstruction constitutes between ro and 15 per cent. of all cases of portal hypertension and is encountered much more frequently in the portal than in the splenic vein. The commoner causative lesions are summarized in Table $I$. Intra-hepatic obstruction is almost invariably due to cirrhosis of the liver. Cirrhosis means a condition of the liver in which death of parenchymal cells has been followed by collapse of the reticular framework of the 'lobules', increased fibrous tissue formation and irregular regeneration of surviving cells. The result is a gross distortion of the architecture and of the vascular pattern of the liver, greatly increasing the resistance to portaio blood flow through it. Such a condition of the liver may be found if recovery occurs after ab. single massive injury such as severe infective oritoxic hepatitis, or may develop over a period of years as a result of repeated chemical or metabolico trauma to the liver. Hepato-lienal fibrosis is the name given to a chronic condition in which botho the liver and spleen are involved. Its aetiology is unknown. It occurs at an earlier age than cirro hosis, not infrequently in childhood. The splenic and hepatic changes are essentially similar to those

Table I

Portal Vein $-\left\{\begin{array}{l}\text { Congenital Obliteration } \\ \text { Angioma } \\ \text { Thrombotic Occlusion } \\ \text { Invasion } \\ \text { Occlusion }\end{array}\right\}$ By Tumour Tissue
Splenic Vein $-\left\{\begin{array}{l}\text { Occlusion by Thrombus } \\ \text { Occlusion by External } \\ \text { Pressure }\end{array}\right\} \begin{aligned} & \text { Scar Tissue } \\ & \text { Pancreatitis }\end{aligned}$




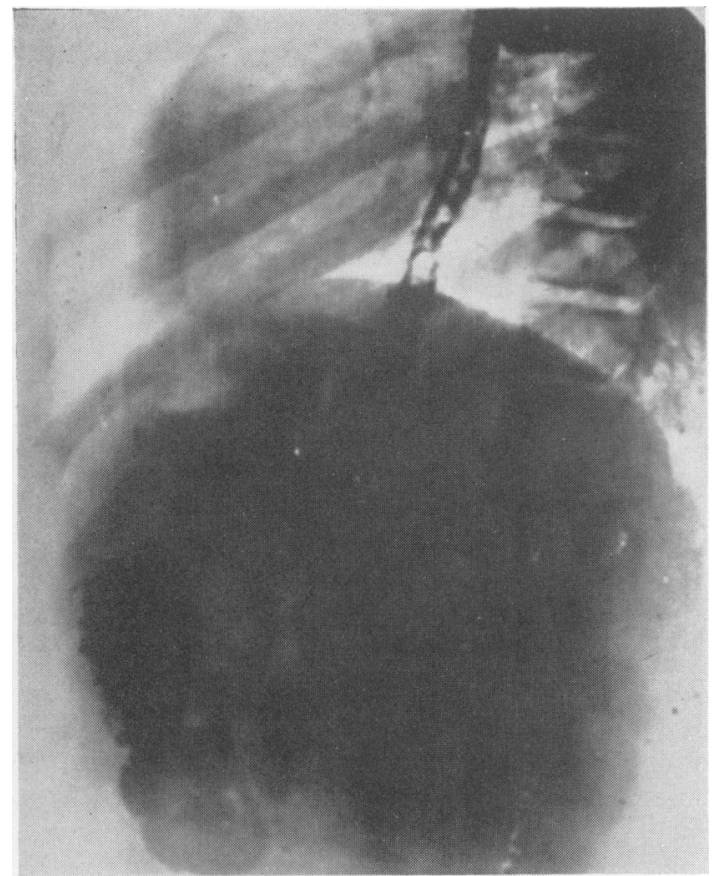

Fig. I.-Demonstration of oesophageal varices by barium swallow.

in cirrhosis, but contrary to the findings in cirrhosis, when the condition first becomes manifest the spleen is usually much enlarged and the liver but slightly affected. This syndrome includes the conditions commonly referred to as Banti's disease and splenic anaemia.

\section{Clinical Features}

The features common to all iorms of chronic portal obstruction are splenomegaly, gastrooesophageal bleeding, the development of a collateral venous circulation and changes in the blood picture. Not all these features are present in every case.

The spleen is enlarged and firm. Occasionally sharp pain is felt over it, probably due to local thrombosis and perisplenitis. Gastro-oesophageal bleeding may be slight in amount and only be detected as 'occult blood' in the stools, or may present as profuse haematemesis. Not infrequently melaena occurs alone. The demonstration of oesophageal varices by $\mathbf{X}$-way (fig. - I) or oesophagoscopy is direct evidence of enlarged collateral channels between the portal and systemic circulations. Sometimes veins radiating from the umbilicus may be seen on the abdominal wall. The direction of flow in these veins is usually towards the superior vena cava. The blood picture shows, singly or in combination, anaemia, leukopenia and thrombocytopenia. Recent obser- vations have demonstrated that the leukopenia and thrombocytopenia are related to enlargement and functional overactivity of the spleen, but that the anaemia cannot be explained in this way (Macpherson and Innes, 1953). It appears in part to be due to blood loss and in part to be a metabolic abnormality, possibly secondary to the hepatic disease.

A history of vague ill-health, fatty dyspepsia and mild jaundice in a middle-aged adult, especially when the patient is known to have suffered from severe infectious hepatitis or been exposed to a hepato-toxic agent, points to the liver as the site of the portal obstruction. The liver is usually enlarged and firm. In some cases it may be smaller than normal and not palpable. Its functional capacity should be estimated from the results of a battery of biochemical tests which should include determination of the plasma albumin concentration, the serum bilirubin and one of the flocculation tests. A strongly positive flocculation test and a plasma albumin below $3 \mathrm{~g}$. per $100 \mathrm{ml}$. or the presence of ascites or oedema of the extremities in the absence of signs of cardiac or renal disease, are evidence of severe hepatic disturbance and contra-indications to any but the most urgent surgery.

The first and often the only feature of extra 0 hepatic obstruction is the occurrence in a healthy child or adolescent of severe haematemesis. In some cases an apparently symptomless splenomegaly may have been detected on a routine medical examination, for example, at school. The liver is normal on clinical examination and by laboratory tests.

\section{Diagnosis}

During a quiescent phase of the disease, a diagnosis of portal hypertension may be made if haematemesis has occurred in a patient with splenomegaly when (I) other causes of splenomegaly such as leukaemia, myelo-sclerosis, Gaucher's disease and haemolytic anaemia are excluded by the blood picture, by marrow examination and lymph gland biopsy. (2) Oesophageal varices can be demonstrated radiographically or through the oesophagoscope. (3) Hepatic function tests are abnormal (approximately 85 per cent. of cases).

Not infrequently the diagnosis of the cause of the splenomegaly can be made only by laparotomy and liver biopsy. In cases of doubt such a diagnostic operation should be done before the definitive procedure is carried out.

The diagnosis during an episode of haematemesis may present considerable difficulty. Bleeding from a peptic ulcer can usually be excluded by the long history of typical ulcer-dyspepsia obtain- 
able in such cases. Sometimes, however, the dyspepsia of chronic liver disease simulates that of an ulcer (epigastric discomfort after meals and waking at night, for example) and during profuse bleeding the spleen may be difficult to palpate. Moreover, the two conditions are not mutually exclusive. Where there is uncertainty as to the diagnosis and where such factors as the age of the patient make an immediate and accurate diagnosis desirable, a barium swallow may be given for the purpose of excluding or confirming the presence of oesophageal varices.

\section{Prognosis}

In extra-hepatic obstruction the prognosis depends upon the incidence and severity of oesophageal haemorrhages, the possibility of their surgical relief and, in young children, upon the co-existence of other congenital anomalies. In intra-hepatic obstruction, the prognosis is largely determined by the degree and type of the hepatic disease. In primary cirrhosis blood loss is badly borne and without suitable surgical treatment tends to recur and to precipitate the onset of hepatic failure, coma and death. The prognosis in hepato-lienal fibrosis is less predictable, many cases running a comparatively benign course with occasional episodes of haematemesis. In the adult with cirrhosis of the liver which is functionally well-compensated under ordinary circumstances, operation should usually be advised. The mere presence of an enlarged spleen and liver in a child is seldom sufficient indication for operation. Surgery should be withheld until there is evidence either of dangerous oesophageal varices or that the presence of the enlarged spleen is actively harmful.

\section{Treatment}

The treatment of active haematemesis in portal hypertension is cautious sedation and transfusion of whole blood in amounts sufficient to maintain a normal blood pressure. The diseased liver is particularly sensitive to anoxia and the invariable sequel to any period of arterial hypotension in such patients is coma and death. If bleeding does not decrease or stop spontaneously it may be controlled by oesophageal tamponnade. This is most successfully performed by passing a special oesophageal tube fitted with balloons which may be inflated to keep the tube in position and to press upon the bleeding vessels in the oesophageal wall (Sengstaken and Blakemore, 1950). Indications for the use of this method of haemostasis or for operative ligation of the varices inside the oesophagus are seldom encountered, for the outcome is usually determined before the patient reaches hospital, by the amount of blood lost in the initial haematemesis and by the capacity of the liver to withstand the ensuing circulatorya depression.

Treatment between bleeding episodes is directed towards:-(r) Improvement of the blood picture.. (2) Improvement of hepatic function. (3) Prevention of further bleeding from oesophageal and? gastric varices.

The acute anaemia which results from severe $\frac{0}{\bar{c}}$ blood loss must be treated by adequate blood? transfusion. Chronic anaemia usually responds to appropriate doses of iron by mouth. Casesw which prove refractory to oral therapy may improve if iron is given intravenously. Persistent granulopenia, especially if it occurs in cirrhosis and is associated with recurring low-grade infecs $\frac{\text { s }}{8}$ tions, and thrombocytopenia with or without are overt purpuric tendency are relieved by splenec tomy alone or combined, where necessary and desirable, with another procedure (see below) Patients with clinical and laboratory evidence of severe liver damage, and in particular those withoo ascites and generalized fluid retention, are not suitable subjects for operation. Medical treat ment (high protein, low sodium diet together with the injection of mercurial diuretics if required) iso instituted to stimulate regeneration of liver cellsand improve hepatic function. Such treatmento may have to be continued for many months before consistent improvement is apparent.

Prevention of further episodes of haematemestis can be achieved only surgically. Operations tơ this end have taken one of five forms:-

(I) Ligature operations either of arteries, e.g. $\frac{\mathrm{Q}}{\mathrm{Q}}$ the splenic artery, in an attempt to reduce the splanchnic inflow, or of the veins to the cardios oesophageal area. These operations are unsound theoretically because collateral circulations develor with great rapidity, and in practice are unpredic table in their results. They should not be per을 formed as an elective procedure. Ligature of the hepatic artery has been advocated as an operation. for cirrhosis with ascites. There is no anatomicab or experimental basis for this operation and pub윽 lished reports indicate that the commonest seque is death from ischaemic necrosis of the liver.

(2) Attempts to improve the collateral circula $\frac{D}{0}$ tion by stimulating adhesions between the surface of the viscera and the abdominal parietes (omenes topexy). This has been practised for many yearsin sometimes successfully, but is unreliable and if done at all should be used to supplement some
other procedure, such as splenectomy.

(3) Splenectomy removes the enlarged spleef and is followed by lasting increase in the number of circulating white blood corpuscles and platelets? It is the operation of choice when splenomegal and an abnormal blood picture are the onl features of portal hypertension. Splenectom 

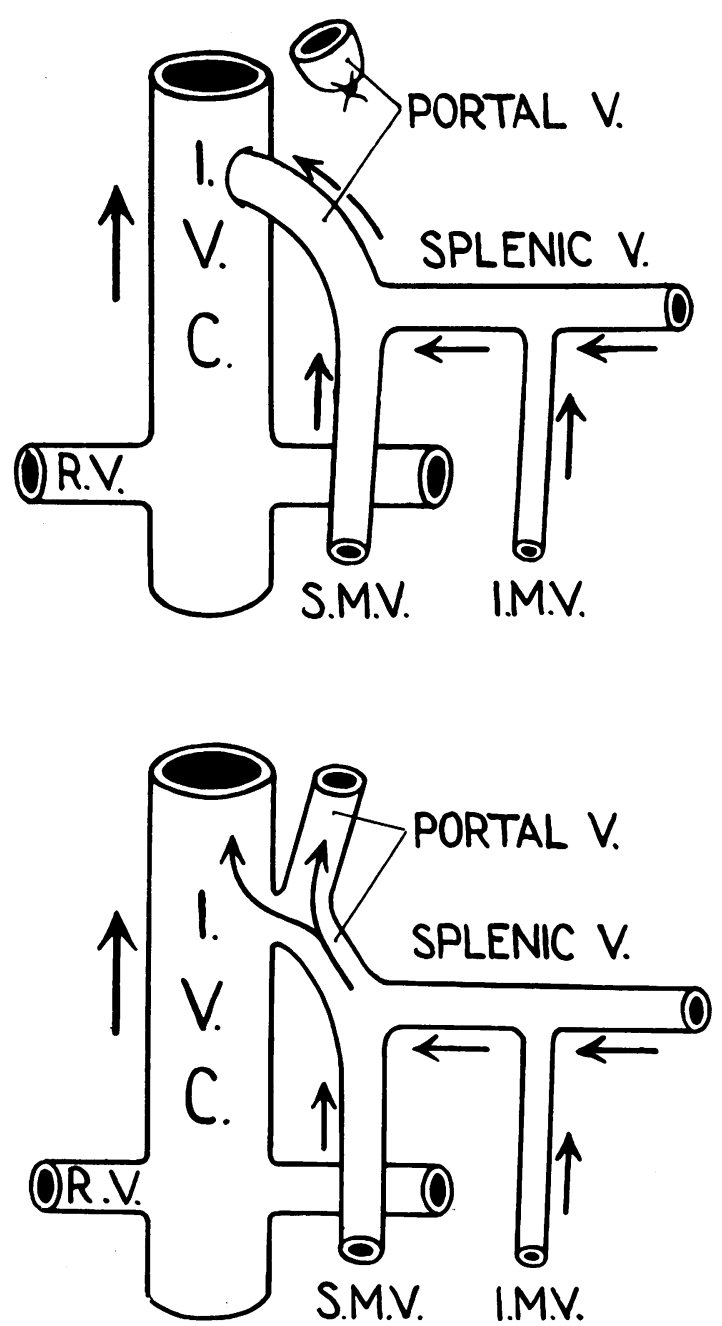

FIG. 2.-The operations of portal-caval anastomosis. (Reproduced from Learmonth (195I), by kind permission of the Edinburgh Medical Fournal).

cures the tendency to recurring haematemesis only when the block is in the splenic vein. It may be combined with a venous anastomosis or with excision of the varix-bearing area (see (4) and (5) below) but in patients who are poor surgical risks, splenectomy alone may be performed in the hope that it may have at least a temporary benefit by improving the blood pict ure.

(4) Attempts to reduce the portal pressure and to divert the portal blood away from the dangerous areas by direct anastomosis of a large visceral to a large systemic vein. Such an anastomosis offers much less resistance to flow than do a cirrhotic liver and the innumerable veins which form the collateral circulation. It can divert a considerable volume of portal blood directly into the systemic
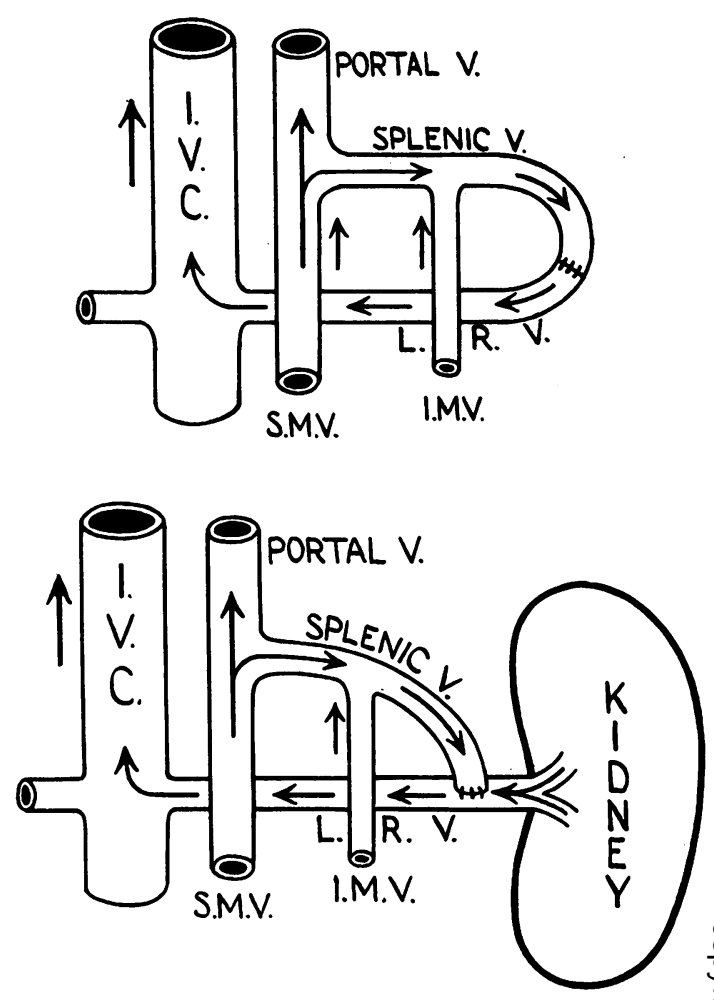

FIG. 3.- The operation of splenectomy and spleno-rena anastomosis. The kidney should be preserved if at all possible. (Reproduced from Learmonth (195I), by kind permission of the Edinburgh Medical fournal).

circulation and may lower the portal pressure materially. The veins generally selected for anastomosis are portal vein and inferior vena cava or splenic vein (after splenectomy) and left renal vein (figs. 2 and 3 ). Originally a cuffed vitallium tube was used to make the venous anastomosis, but this method has now been abandoned in favour of suture with fine braided silk. The choice of operation will be influenced by such considerations as:-(a) the site of the obstruction, e.g., thrombosis in the portal vein precludes the use of that vein for purposes of anastomosis. (b) The condition of the veins. Either the splenic or the renal vein may prove to be unsuitable because it is not a single trunk. Occasionally sclerotic changes are found in the portal and splenic veins. (c) The desirability of removing the spleen.

These are difficult operations to perform, demanding good anaesthesia and meticulous surgical technique. It is still not known how often the anastomosis remains patent or how effective the operations are in preventing further haematemesis.

(5) Excision of the varix-bearing area, generally 


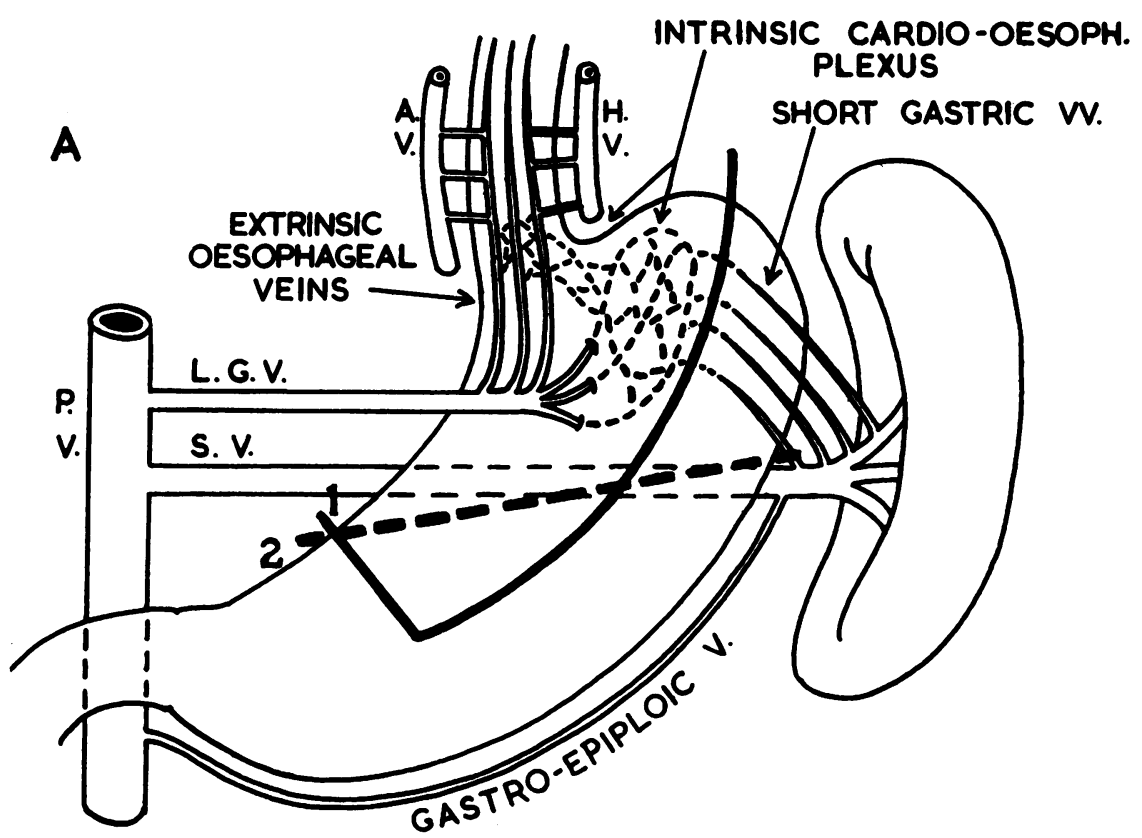

FIG. 4.-Diagram to illustrate the venous connections of the varix-bearing area and the operation of limited oesophago-gastrectomy. I,ine I indicates the line of distal section through the stomach that may be used when the spleen has already been removed. Line 2 is preferable when splenectomy is performed at the same time.

combined with splenectomy. The varix-bearing area (fig. 4) comprises the lowest 5 to $8 \mathrm{~cm}$. of oesophagus, the cardia, the fundus immediately beside the cardia and the segment of the stomach drained by the left gastric vein (Butler, 195I). Excision of this area followed by end-to-side oesophago-gastrostomy is designed to remove the source of the haemorrhages. This operation is liable to the same complications as oesophagogastrectomy for other conditions and imposes a considerable strain on the patient. For this reason it should probably be reserved for young persons with moderate impairment of hepatic function and for those who have had recurrent haematemesis after some other surgical procedure.

In all cases of portal hypertension, but especially in those with hepatic disease, the operative risk is considerable. Even in the most experienced hands (Blakemore, I95I; Learmonth, 1952) it was 20 per cent. in cases with hepatic involvement. Operation should be undertaken only in properly equipped hospitals by teams who are aware of and can take precautions against these risks. The use of an abdomino-thoracic approach greatly facilitates the performance of oesophago-gastrectomy and of the operations of venous anastomosis. It is usually possible to select the suitable operation beforehand, but it is advisable to explore the abdomen before the chest is opened to determin the pathology and in particular the condition of the portal vein.

The peculiar risk of operation in intra-hepatic portal obstruction is the occurrence of post-을 operative hepatic failure. In general, the worsethe results of the preliminary hepatic function tests, the greater is this risk. Two precautions may be taken during surgery. The anaesthetic should be chosen so as to allow a high percentages of oxygen to be given continuously, relaxation. being secured by agents with a curariform action? and blood loss should be replaced as it occurs soై that at no time is the circulating blood volumes significantly reduced.

In extra-hepatic block in which the obstruction can be circumvented, the prognosis after operation is good. It will be realized that in intra-hepatic obstruction operation can relieve only the haema N temesis. The prognosis remains that of the hepatic disease.

\section{BIBLIOGRAPHY}

BLAKEMORE, A. H. (1951), 7. Amer. med. Ass., 145, 1335 BUTLER, $\mathrm{T}$, A. H. (1951), 6,276

LEARMONTH, SIR JAMES (I95I), Edin. med. $f$., 58, I.

LEARMONTH, SIR JAMES (1952), quoted by McNee, Sir John, and Macpherson, A. I. S., in 'British Encyclopaedia of Medicat Practice,' second edition, II, 459 . London: Butterworth. MACPHERSON, A. I. S., and INNES, J. (1953), Lancet, I, 1120 . D SENGSTAKEN, R. W., and BLAKEMORE, A. H. (1950), Ann? Surg., 131, 781. 